\title{
A Study on the Construction of Model of Scholarship of Teaching for College English Teachers
}

\author{
Zhiming Tang \\ International College, Fujian Agriculture and Forestry University, Fuzhou, China \\ Email:000q110120@fafu.edu.cn
}

How to cite this paper: Tang, Z.M. (2021) A Study on the Construction of Model of Scholarship of Teaching for College English Teachers. Open Access Library Journal, 8: e7842.

https://doi.org/10.4236/oalib.1107842

Received: August 9, 2021

Accepted: September 23, 2021

Published: September 26, 2021

Copyright $\odot 2021$ by author(s) and Open Access Library Inc.

This work is licensed under the Creative Commons Attribution International License (CC BY 4.0).

http://creativecommons.org/licenses/by/4.0/

\section{(c) (i) Open Access}

\begin{abstract}
Based on the analysis and research of many theoretical documents on the connotation scholarship of teaching, this paper refines the core connotation of the universality of teaching scholarship, and develops a data scale based on this. Through exploratory factor analysis and confirmatory factor analysis, a questionnaire survey was conducted among teachers of public English departments of four universities in Fuzhou, Fujian Province, and it is concluded that the core factors of teaching scholarship are learning and researching of teaching, peer communication, teaching feedback, and professional knowledge.
\end{abstract}

\section{Subject Areas}

Linguistics

\section{Keywords}

College English Teachers, Teaching Scholarship, Influencing Factor

\section{Introduction}

In the 1990s, Boyer proposed that a professor's academic work should be evaluated in four ways: scholarship of discovery, scholarship of integration, scholarship of application and scholarship of teaching. Teaching scholarship refers to the fact that teachers in colleges walk away from the pure research of scientific problems, build a bridge between knowledge discovery and knowledge imparting, and impart disciplinary expertise to students in an effective way [1]. However, teaching scholarship is not only the study of how to impart professional knowledge to college teachers but also the study of how students learn know- 
ledge, so as to more effectively achieve the dissemination of knowledge and teaching [2].

Teaching scholarship has the characteristics of scientific research. First, in terms of process, the process of practical teaching scholarship is the same as the traditional scientific research; it has to go through the problem selection, find the relevant resources, establish the solution to the problem, implement the solution, and analyze and test the results. It's a process of exploration and discovery. Second, the results of teaching scholarship can be very valuable, and can be published, publicly communicated and so on. This makes teaching academic [3].

The evaluation of teaching scholarship depends on the definition of teaching scholarship concept. Since 1990, the definition of teaching scholarship has remained at the level of theoretical exposition, and different people have different definitions. Boyer came up with the concept of teaching scholarship, but did not give an operable definition. If we take Boyer's report in a colloquial sense, teaching scholarship refers to the knowledge that the teacher imparts, which takes place in a university classroom and is carried out by a university teacher. The teaching scholarship is the comprehensive utilization of the teacher's teaching knowledge and ability. A university teacher who has a good teaching scholarship is a teacher who has a wide range of knowledge and continuously deepens intelligence. He is both a teacher and a student. The core of teaching scholarship is that teachers impart an understanding of subject knowledge and professional areas to students through teaching techniques. Teaching scholarship comes from teachers' teaching practice, which is the experience summary and theory sublimation of teaching practice. It runs through the whole process of teacher's teaching, and it can produce academic achievement and have a significant influence like other scholarships. If we want to give a definition of teaching scholarship, teaching scholarship is an activity carried out by teachers on the basis of their understanding of the subject, exploring and communicating the problems existing in teaching practice. It can form research results and have a significant impact. After Boyer came up with the concept of teaching scholarship, his successor, Shulman, took over and developed his ideas. In his opinion, teaching and learning are closely connected and cannot be separated in higher education, so the level of teaching scholarship involves not only the teaching of teachers, but also the study of students. Teaching is a kind of public wealth, and communication is the most important factor. The group of university teachers is an active group. They often talk together, evaluate each other, and exchange teaching methods and contents. Shulman believes that teaching scholarship should be both a scholarship about teaching and a scholarship about learning, a study of the problems that arise in the process of teaching and learning. Just as the students' learning style is different, the teaching style of university teaching should be different too. Teachers perceive their own teaching situation and adopt different teaching styles. And sometimes the results can be different even with new teaching methods. From this, he put forward "the scholarship of 
teaching and learning". Thus, Scholarship of Teaching (SOT) becomes Scholarship of Teaching and Learning (SOTL).

Besides, he also answers the question of why teaching is scholarship. Shulman argues that teaching can become scholarship mainly based on the following two points: First, in the terms of process, the process of practical teaching is the same as that of traditional scientific research. They have to go through the problem selection, find the relevant resources, establish the solution to the problem, implement the solution, and analyze and test the results. It's a process of exploration and discovery. Second, the results of teaching and learning can be very valuable, can be published, publicly communicated and so on. This makes teaching academic.

Therefore, we can see that compared with Boyer, Shulman not only stresses teacher's teaching researches in teaching scholarship, but also pays more attention to student learning research. Increase teachers' understanding of effective learning styles and factors that hinder learning. He believes that studying the impact of student learning influencing factors is more important in teaching scholarship.

In 2000, Kreber used Mezirow's Theory of Transformative Learning in a paper exploring the scholarship of teaching and developed a nine-dimensiona model of teaching scholarship. In this paper, Klaber defines teaching scholarship as learning teaching knowledge and demonstrate teaching knowledge continuously. According to Mezirow's theory of transformative learning, individual knowledge is formed through three levels of reflection, based on content reflection, process reflection and premise reflection. Based on this, he proposed that these three reflections bring three kinds of knowledge in the teaching field: instructional knowledge, pedagogical knowledge and curricular knowledge [4].

She later published the Controversy and Consensus on the Scholarship of Teaching in Studies in Higher Education in 2002 [5]. In order to clarify the various viewpoints and views surrounding the connotation of the concept of teaching scholarship over the years, this academic paper uses a unique research method, Delphi survey, to survey 11 experts who have made great achievements in the field of teaching scholarship and they were asked to answer the questions about the core characteristics or elements of teaching scholarship. After getting responses from 48 different traits, the experts were asked to rate the 48 traits on a scale of 1 to 7 for their level of approval. After analyzing the data, the authors found that the experts had a high degree of agreement on the 6 characteristics. The six characteristics are:

1) Exploring the relationship between teaching, learning and research, integrating and applying knowledge;

2) Implement effective teaching through the knowledge gained in teaching practice and can stand up to the traditional discipline-based proof of academic standards such as publish publicly, peer review and so on;

3) Acquire knowledge about teaching and learning through reflection on practice 
4) Specific research capabilities, attitudes, and outcomes;

5) Acquire the development of pedagogical knowledge content through reflection;

6) Information and perspective sharing and peer reviews.

According to Kraber's research, we can find that the six characteristics of teaching and learning mainly focus on these points: teaching and research on the combination of theory and practice, knowledge innovation, academic ability, sharing and communication.

Michael Theall [6] discusses teaching scholarship from a larger perspective. They believe that teaching scholarship exists at the level of individual teachers, as well as at the level of departments and schools. When evaluating each level, three important aspects should be considered, namely, sharing of teaching, students' learning achievements and related teaching practice, and innovation of subject knowledge and teaching method knowledge. Trigwell [7] [8] constructs a concept of teaching scholarship that tends to be practical. He thinks that teaching scholarship is made up of three related elements, namely knowledge, practice and achievement. Among them, knowledge includes three aspects: the knowledge of teaching and learning theory, the concept of teaching and learning, subject knowledge; Practice includes teachers' teaching behavior, investigation and evaluation of teaching and students' achievements, reflection on teaching, communication and learning activities, etc. The achievement factors include students' learning achievement, teachers' teaching and learning research papers, and teachers' satisfaction. In 2004, Pat Hutchings, then vice president of the Carnegie Foundation for the Advancement of Education, gave a speech in which he stated that the idea of teaching scholarship was to bring academic values, habits and academic skills into teaching and learning, explore how we students learn, and design research methods for such questions and share them with our colleagues. Thus it can be seen, the Carnegie Foundation for the Advancement of Education has a clearer definition of the concept of teaching scholarship than did John Boye, who first proposed it: teachers use academic attitudes, norms, and methods to research, analyze, refine, and share and receive criticism of issues arising in the practice of teaching and learning, so as to enrich the knowledge of teaching and learning and improve the quality of students' learning. Only in this way, teaching scholarship can be both practical guidance and creative knowledge, and it can enjoy the same treatment as traditional academic research.

Up to now, there has not been a certain consistency in the definition and evaluation methods of teaching scholarship, but it is precisely because of this openness that the research in this field is full of vitality and innovation, one of its most important contributions was that people began to reflect on the relationship between teaching, especially the relationship between education and scientific research in institutions of higher education, breaking the dichotomy of teaching and scientific research, and thinking more about the integration of teaching and scientific research, as well as mutual promotion of the internal machine, the importance of teaching also reached an unprecedented height. 
In China's educational environment, the Ministry of Education's reform of the evaluation of university teachers, which breaks the five-only rule, to a certain extent coincides with the theory and practice of teaching and learning, and reflects the student-centered nature of higher education.

Since the concept of teaching scholarship came into being, all the participants of teaching and research have explored the connotation, evaluation system and practical feasibility of teaching and learning from their own perspective. However, few people pay attention to the enlightenment of the concept to teachers' professional development. This paper, from the perspective of a college English teacher, attempts to explore the factors that influence the academic development of college teachers in order to provide suggestions and directions for the autonomy of teachers' professional development.

\section{Confirmatory Study}

Based on the theory of Teaching scholarship Connotation, the author has developed an academic questionnaire for college English teachers, which is based on teaching scholarship theoretical framework proposed by Kreber [5] [6], Michael [7], and Trigwell [8]. The questionnaire consists of items that cover teaching knowledge, teaching and research practice, teaching communication, and reflection. The purpose of this questionnaire is to obtain information of college English teachers in Fujian Province about what they know and what they do in their teaching career in regard to teaching scholarship. The data collected at this stage will be used for the exploratory factor analysis, so as to establish college English teachers' teaching scholarship influence factors in teaching, and then, the questionnaire is used in a larger sample consisting of key teachers of English in colleges and universities from all over the country, to test and revise the model, and to get the final teaching scholarship impact factor model.

\subsection{Exploratory Factor Analysis Study}

The establishment of the model of teaching scholarship influencing factors depends on the determination of the factors which are included in teaching scholarship. At present, there is no direct exposition of the influential factors of the teaching scholarship of university teachers in the foreign theoretical research literature, but we can see it indirectly through the criteria of their evaluation of teaching scholarship. In fact, the following factors have a greater impact on the teaching scholarship: Teachers have teaching knowledge and professional knowledge which are the teacher's knowledge system and sharing and communication between teachers and colleagues or experts. However, for college English teachers, their academic impact factors can only be explored by collecting the sample data of college English teachers.

\subsubsection{Research Tools}

The research instrument is a questionnaire on college English teachers' teaching scholarship, which is based on foreign teaching scholarship theories, mainly re- 
ferring to the theories of Kreber [4] [5], Michael [6], and Trigwell [7] [8], and combining with the author's work experience. The questionnaire is divided into two parts, the first part is personal information, such as age, sex, length of education, educational background and so on. The second part consists of 19 items. After the questionnaire is designed, the author first tests the reliability and validity of the questionnaire in the Public English Teaching Department of my own school, and then made some improvements on the wording.

\subsubsection{Subject}

At the exploratory study stage, 226 public foreign language teachers from four provincial universities in Fujian province were surveyed. Among the four universities are one comprehensive university, one agricultural and forestry, one science and engineering university and one normal university. The overall situation of all teachers who participated in the effective survey is as follows:

As can be seen from Table 1, the participants in the survey are mainly female college teachers $(77.9 \%)$, and the majority of the interviewed are lecturer professors (61.9\%) in their own universities. As for their current academic degrees, most of them hold a master's degree, with $60.5 \%$. In terms of teaching experience, approximately a third of the respondents have less than 5 years of working experience as college English teachers, and $45 \%$ are in the range of 5 to 10 years of experience, and a quarter of these teachers have more than 10 years of teaching experience.

\subsubsection{Data analysis Results}

\section{1) Reliability analysis}

Through the reliability test of SPSS 20.0 software, the CRONBACH's Alpha of the questionnaire is shown in Table 2: from the Alpha value, each section is as high as 0.8 or above. The results of KMO and Bartlett's test as shown in Table 3 indicate that Chi-square $(171)=3092.336, \mathrm{P}=0.000$, and the $\mathrm{KMO}$ value was. 943. KMO above 0.9 is very good, $0.8-0.9$ is good, $0.7-0.8$ is fair, so the sample data is suitable for factor analysis.

\section{2) Factor analysis results}

By using principal component analysis and maximum variance method, we find that there are 4 factors that constitute the influencing factors of teaching scholarship. According to the description of the items corresponding to each factor, we named them "teaching study and research", "teaching communication”, "professional knowledge”, "teaching feedback acquisition”. Specific load values are shown in Table 4.

Table 1. A descriptive statistics of the participants.

\begin{tabular}{|c|c|c|c|c|c|c|c|c|c|c|c|c|}
\hline \multirow{2}{*}{$\begin{array}{c}\text { Gender \% } \\
\mathrm{M}\end{array}$} & \multicolumn{4}{|c|}{ Title $\%$} & \multicolumn{4}{|c|}{ Academic qualifications \% } & \multicolumn{4}{|c|}{ Teaching Length (years) \% } \\
\hline & $\mathrm{F}$ & Prof. & Ass. Prof. & Lec. & T.A. & Ph.D & M.A. & B.A & $<5$ & $5-10$ & $11-15$ & $>15$ \\
\hline 22 & 78 & 0 & 21.8 & 61.9 & 16.3 & 0.4 & 60.2 & 39.4 & 29.3 & 45 & 23 & 2.0 \\
\hline
\end{tabular}


Table 2. Confidence test.

\begin{tabular}{cc}
\hline Cronbach's Alpha & Number of items \\
\hline 95 & 19 \\
\hline
\end{tabular}

Table 3. KMO and Bartlett's test.

\begin{tabular}{cc}
\hline \multicolumn{2}{c}{ Kaiser-Meyer-Olkin metric for sampling adequacy 0.943} \\
\hline & Approximate cardinality 3092.336 \\
\cline { 2 - 2 } Bar Bartlett's sphericity test & Df171. \\
& Sig. 000 \\
\hline
\end{tabular}

Table 4. Factor loadings table.

\begin{tabular}{ll}
\hline \multicolumn{1}{c}{ Factor load } & \\
\hline $\begin{array}{l}\text { Factor 1-Teaching Learning and Research (8 observed variables) } \\
\text { (q15) Change teaching methods and strategies according to students' situation }\end{array}$ & 0.822 \\
(q3) Compare the effect of different teaching methods in teaching & 0.774 \\
(q2) Often read books about how students learn English & 0.749 \\
$\begin{array}{l}\text { (q14) Implement classroom research and apply the results to classroom teaching to } \\
\text { improve the quality of teaching }\end{array}$ & 0.738 \\
(q1) Keep absorbing the knowledge of English teaching theory & 0.669 \\
(q16) Apply the results of teaching research in literature to our own teaching practice & 0.664 \\
(q17) Try Out a new teaching method and observe its effect on teaching & 0.563 \\
(q4) Read articles on English learning styles and strategies frequently & 0.542 \\
\hline
\end{tabular}

Factor 3-Expertise (3 observed variables)

$\begin{array}{ll}\text { (q5) Have solid English professional knowledge } & 0.775\end{array}$

$\begin{array}{ll}\text { (q6) Solid knowledge of English teaching } & 0.724\end{array}$

(q7) Have sufficient knowledge of educational theory

Factor 2-Instructional Communication (5 observed variables) 0.661

(q9) Communicate with colleagues about English teaching contents or methods $\quad 0.818$

(q13) Research findings in communication teaching with colleagues $\quad 0.754$

(q10) Communicating with colleagues about students' English learning 0.703

$\begin{array}{ll}\text { (q12) Share lesson preparation with colleagues } & 0.680\end{array}$

(q11) Listening to expert lectures and learning teaching methods $\quad 0.655$

Factor 3-Expertise (3 observed variables)

$\begin{array}{ll}\text { (q5) Have solid English professional knowledge } & 0.775\end{array}$

$\begin{array}{ll}\text { (q6) Solid knowledge of English teaching } & 0.724\end{array}$

$\begin{array}{ll}\text { (q7) Have sufficient knowledge of educational theory } & 0.661\end{array}$

Factor 4-Instructional feedback acquisition (3 observed variables)

$\begin{array}{ll}\text { (q8) Invite your colleagues to observe your class and get their opinions } & 0.794\end{array}$

$\begin{array}{ll}\text { (q19) Collect students' opinions on teaching } & 0.763\end{array}$

$\begin{array}{ll}\text { (q18) Collect students' feedback on their English learning } & 0.700\end{array}$ 


\subsection{Confirmatory Factor Analysis Study}

According to the results of exploratory factor analysis, the final questionnaire consists of four parts, a total of 19 items. The four parts are teaching study and research, teaching exchange, professional knowledge learning, teaching feedback acquisition. At the end of May 2013, the questionnaire was distributed to a wider sampling population for confirmatory research. This time, foreign language teachers from universities all over the country who were studying in Shanghai were sampled. A total of 350 questionnaires were distributed, 321 of which were returned, and 294 questionnaires were valid, excluding those made by non-English teachers. The KMO value was $0.941, \mathrm{P}=0.000$, Cronbach Alpha value was 0.959, and the reliability and construct validity of the data were good (as shown in Table 5). The final model is shown in Figure 1.

Table 5. Model fitting indicators.

\begin{tabular}{ccccccccccc}
\hline DF & X2 & P & NFI & CFI & IFI & GFI & AGFI & RFI & RMR & RMSEA \\
\hline 142 & 435.58 & 0.47 & 0.96 & 0.97 & 0.97 & 0.95 & 0.93 & 0.95 & 0.02 & 0.00 \\
\hline
\end{tabular}

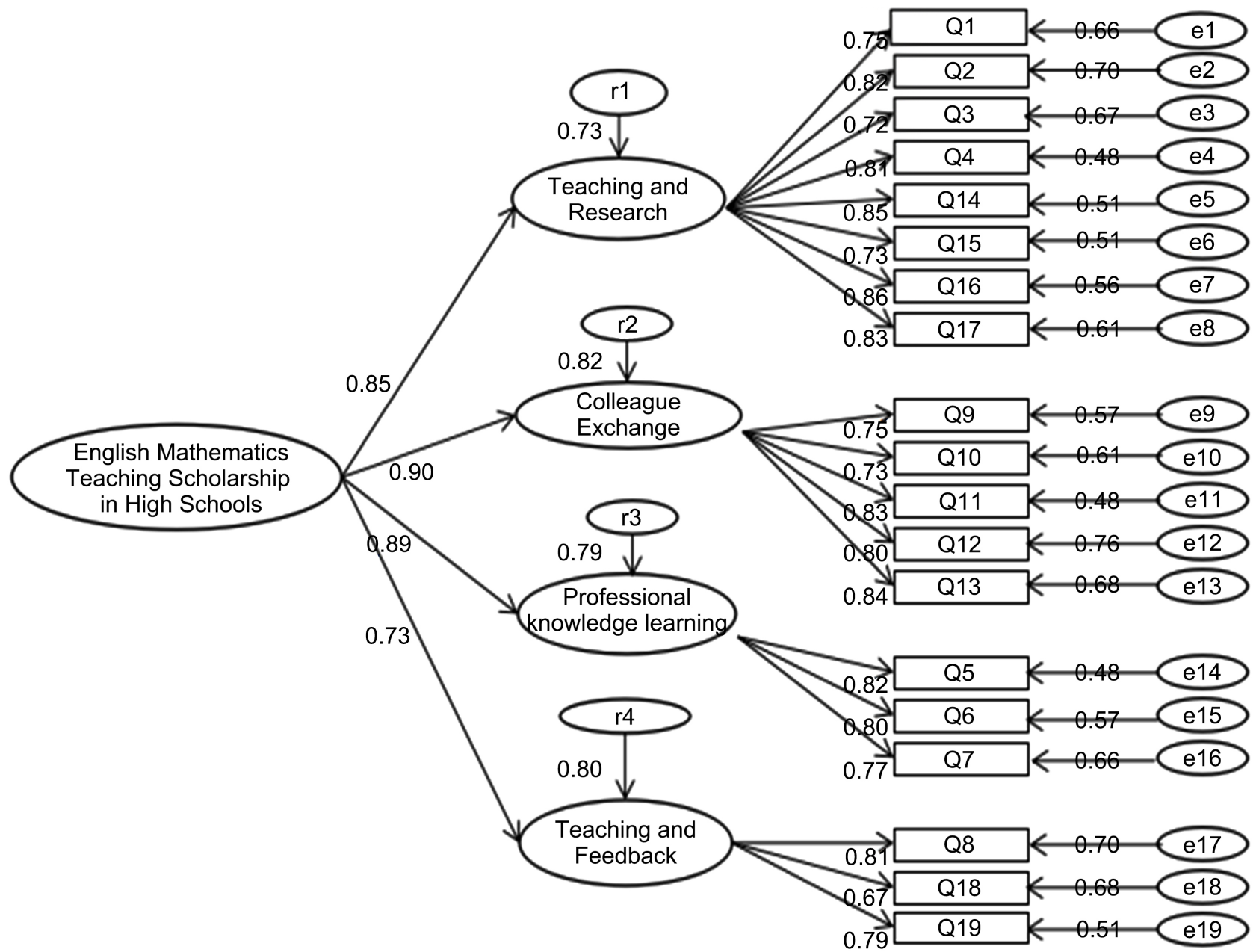

Figure 1. The model of teaching scholarship for university foreign language teachers. 


\section{Analysis of Results and Discussion}

We found theoretical justifications for all four factors. Kreber's theory of pedagogical scholarship, in which the nine components of knowledge acquired through learning at three levels and reflection at three levels are central to his theory of pedagogical scholarship, was found to be constrained by the presence or absence of the two actions of learning and reflection and the results obtained by teachers. The concepts of pedagogical learning and research, and the acquisition of pedagogical feedback, among the four factors derived from this factor study, are essential concepts of reflection and learning. The professional knowledge (including general pedagogical knowledge, pedagogical knowledge, and subject matter pedagogical knowledge) is largely consistent with Kreber's proposal that teachers acquire three types of knowledge in the process of reflection and learning. The three types of knowledge he proposed are: pedagogical knowledge, instructional knowledge, and curricular knowledge.

Micheal Theall argues that the influences on the scholarship of teaching and learning exist at the level of the individual teacher, as well as at the departmental level and the school level. Attention must be given at each of these levels. $\mathrm{He}$ suggests that at the faculty level, whether teachers share in teaching and learning, as well as differences in teachers' teaching practices and innovations in subject matter knowledge and pedagogical knowledge are the three most important elements that influence the scholarship of teaching and learning. This current research focuses on the level that is primarily based on teachers. Communication among the four influencing factors derived from the factor analysis study is conceptually similar to Micheal Theall's shared teaching; while learning and research in teaching fall under Micheal Theall's conceptual umbrella of teaching practices and innovations in pedagogical knowledge; and expertise can be understood as part of innovations in disciplinary knowledge.

Therefore, it can be seen that the influence factors of teaching scholarship obtained by factor analysis in the current research overlap and approximate each of Micheal Theall's and Kreber's theories. In short, the hypothesis model based on the data of public English teachers in Chinese universities, after empirical analysis and validation, the resulting four-factor theory of teaching scholarship of English teachers in universities can be said to be derived from the related theory of teaching scholarship of Kreber et al. It validates Kreber et al.'s research theory and also enriches the application of pedagogical scholarship among college English teachers.

The academic influence factors of English teachers in higher education are feedback acquisition, communication, expertise, and learning and research in teaching. The four factors are: feedback acquisition, which means English teachers pay attention to their colleagues' evaluation and feedback on their teaching, and English teachers obtain information from students about their English learning and English teaching. Teaching communication includes communication with colleagues about content, methods, and effectiveness, as well as sharing teaching 
skills with experts by attending lectures or seminars. There are three areas of expertise: subject matter expertise, subject matter pedagogy, and general pedagogical knowledge. It reflects the professional level of English teachers in their work in English education at the university level. The meaning of learning and research of teaching is the reflection of teachers on their teaching work and the teaching research conducted on this basis to improve the quality of teaching. Teachers of English in colleges and universities need to improve four aspects of teaching feedback, teaching communication, teaching, learning and research, and professional knowledge in order to improve their own academic level of teaching, and the improvement of academic level of teaching will also improve the quality of teaching in the university itself to achieve the task of training talents in the university and enrich the academic achievements of teachers themselves.

Firstly, feedback is obtained. Feedback is obtained in two ways, firstly, from colleagues. Teachers can reflect on and improve the content of teaching feedback, which is conducive to generating new ideas and methods, not only to improve the professional level of English teachers, but also to transform it into theoretical achievements and improve teachers' theoretical cultivation. Professor Shu Dingfang once said that the most serious problem of English education in China is the lack of theoretical cultivation, and teachers teach English on the stage basically as they learned it from their own teachers in the past. This is why Chinese English education still does not have a method to improve the quality of English education in China [9]. Secondly, we need to learn from the students. Students' opinions and suggestions about teaching and learning, as well as their own feedback on English language learning, including their successes and failures, should be obtained from them. Bruce Albert, former president of the National Academy of Sciences, once pointed out that when students interact with each other, they are not able to understand their own experiences. Albert, former president of the National Academy of Sciences, noted that when students and researchers explore together, there is a much greater chance of the "serendipitous collision of ideas" that is necessary for teachers' continued creativity [10]. Put another way, teachers get feedback from students as a reflection of their ability to enter their mental world, to listen to them, and to grasp their ideas, while at the same time making it easier for students to enter their own educational and academic worlds. English education involves a great deal of psychological knowledge, and it is not easy for English teachers to master this knowledge, but by interacting with students and listening to their feedback, teachers can penetrate into their psychology and understand their needs, thus gaining first-hand information about the teaching objects, and teachers can adjust and improve their teaching based on the information gained, which improves the quality of teaching and, more importantly, the quality of teaching. What is more important is to have a comprehensive dialogue with students, which is what is lacking in higher education, and what should be valued in higher education.

The second factor is instructional communication. There are three levels of 
teaching communication that teachers engage in. The first level is to learn and exchange experiences. Some teachers are good at describing their experiences and allowing other teachers to learn from their successes and failures. Such experiences and lessons are very valuable assets, and English teachers should pay more attention to learning and absorbing such exchanges, combining their teaching experiences and insights to form principles, principles, and theories about teaching and learning and to improve their professionalism. The second level of communication is consultative and advice-based interaction. In order to improve teaching, teachers should point out problems in each other's teaching, help each other, and make suggestions for solving them. The third level of this interaction is research and teaching-style interaction, such as interaction with experts, listening to their reports, and using problems in teaching practice as an opportunity for in-depth discussions around a particular perspective, all of which have a direct impact on the formation of problem-solving strategies and theories of action, and also enrich teachers' academic research horizons.

The third one is learning of professional knowledge. Knowledge plays a central role in professional job performance. Teaching English at the university level is a highly specialized task in education, and it is clear that the knowledge of English teachers is the basis for their work and for their excellence in teaching and scholarship. Karsen's study of the classroom teaching of four beginning biology teachers found that teachers tended to pass the time by assigning classroom and non-laboratory assignments when teaching and explaining sections with which they were less familiar. Good noted that when teachers are not sure how to teach a course, they tend to assess students' learning by reading from the textbook or assigning classroom work or multiple-choice questions to students [11]. College English teachers' teaching is very practical and fundamental, and it is more important for English teachers to be deeply familiar with the basic theories and knowledge of pedagogy and to integrate them with professional subject knowledge through practice, and to establish their own or learn from the subject teaching knowledge already established by their predecessors as soon as possible, so that teaching can become relevant and efficient.

The last one is the awareness of learning of teaching and research. For a long time, many people, including English teachers themselves, have had an incorrect understanding that English teaching is a simple and repetitive job, a textbook and a teaching reference, and they continue to teach year after year without changing the textbook. This understanding can lead English teachers into a vicious circle, i.e., they are buried in simple and repetitive English teaching, resulting in insufficient theoretical training, which in turn leads to the inability to raise to a higher level of teaching, and they can only teach simple and repetitive English all the time. In the academic model of teaching in this study, the meaning of the factor of learning and research in teaching is that teachers should conduct research on teaching in order to improve their teaching and academic level. Then teachers must first have a sense of pedagogical learning and research. 
The teaching of English provides a natural ground for this, because English teaching is full of problems, and the student population is constantly changing, with their age, upbringing, educational background, and so on, all having an impact on the English performance of each class of students. English teachers are unaware of this natural treasure trove of research and experimentation, which is actually a lack of a learning mindset and a sense of research. Teachers who avoid problems and simply take them for granted are naturally unable to grow. Specifically, English teachers should start from these three aspects. First, keep up with the latest theoretical research, so that when problems arise in teaching practice, they can make connections between theory and problems. This is the most immediate change that learning to teach can bring to English teachers. Second, remain highly sensitive to the practice of teaching. Maintain a high degree of sensitivity to the phenomena in the classroom, to changes in the state of students' English learning and learning outcomes, even small changes. This is a constant source of research inspiration for English teachers. Be interested in teaching phenomena and teaching environments, distill and discover problems from these teaching phenomena, and seize meaningful and valuable questions for reflection. Finally, pay attention to the combination of practice and theory. The problems found in teaching should be put back into theory to be interpreted, studied and solved, so that theoretical innovation can be formed. In short, finding the combination of theoretical learning and teaching research practice in teaching is the source of English teachers' own development.

\section{Research Shortcomings and Expectations}

The shortcomings of this study are that the number of questionnaires used in the exploratory factor analysis and validation factor analysis phases was not large enough. Secondly, the number of questions in the questionnaire is only $19 . \mathrm{Ob}-$ viously, if the number is higher, there may be more implied factors. The teaching academic factors are not necessarily limited to the four mentioned in this thesis. If we consider objective factors, such as age, title, gender, etc., they may be influential factors of scholarship of teaching. This thesis explores the factors mainly from a subjective perspective, and the conclusions may not be comprehensive. Second, this study explores the teacher perspective, so if more perspectives are considered, such as the organizational context perspective (i.e., college, school perspective), the conclusions will definitely be more meaningful.

This study can be used as an example to provide a perspective for later researchers, and subsequent related studies that can be conducted in the future include the analysis of factors affecting the teaching scholarship of teachers in other disciplines, the analysis of factors affecting the organizational environment of teaching scholarship, and the analysis of objective factors affecting the subject of teachers in teaching scholarship; the issue of evaluation indicators for teaching scholarship can also be explored, which is beneficial to the current academic evaluation system. 


\section{Note}

This research is one of the results of a school-level project funded by Fujian Agriculture and Forestry University: "Study on the Autonomy of Young English Teachers' Professional Development (No. 111416X1804)”.

\section{Conflicts of Interest}

The author declares no conflicts of interest.

\section{References}

[1] Boyer, E.L. (1990) Scholarship Reconsidered: Priorities of the Professoriate. Jossey-Bass, San Francisco, 16-24.

[2] Healey, M. (2011) Excellence and Scholarship in Teaching: Some Reflections. In: Hay, I., Ed., Inspiring Academics. Learning with the Worlds Great University Teachers. Open University Press, Maidenhead, 198-207.

[3] Spake, E. and Salem, A. (2005) Setting the Stage: the Scholarship of Teaching and Learning. Journal of Therapy Education, 19, 5-13. https://doi.org/10.1097/00001416-200510000-00003

[4] Kreber, C. and Cranton, P.A. (2000) Exploring the Scholarship of Teaching. The Journal of Higher Education, 71, 476-495.

https://doi.org/10.1080/00221546.2000.11778846

[5] Kreber, C. (2002) Controversy and Consensus on the Scholarship of Teaching. Studies in Higher Education, 27, 151-167. https://doi.org/10.1080/03075070220119995

[6] Theall, M. and Centra, J.A. (2001) Assessing the Scholarship of Teaching: Valid Decisions from Valid Evidence. New Directions for Teaching and Learning, 2001, 31-43. https://doi.org/10.1002/tl.14

[7] Trigwell, K., Martin, E., Benjamin, J. and Prosser, M. (2000) Scholarship of Teaching: A Model. Higher Education Research and Development, 19, 155-168. https://doi.org/10.1080/072943600445628

[8] Prosser, M. and Trigwell, K. (2005) Understanding Learning and Teaching: The Experience of Higher Education. Society for Research into Higher Education and Open University Press, Buckingham.

[9] Shuang, D.F. and Zhuang, Z.X. (2008) Modern Foreign Language Teaching: Theory, Practice and Methods. Shanghai Foreign Language Education Press, Shanghai, 4.

[10] Qing, N. (2012) Teaching as a Scholarship. Fudan Education Forum, 4, 1-2.

[11] Good, T.L. and Brophy, J.E. (2002) Perspectives on the classroom. Translated by Tao Zhiqiong, et al., China Light Industry Press, Beijing, 140. 